\title{
Experimental Study Regarding The Influence Of Compliant Hinges Geometry In Mechanical Structures
}

\author{
D. LATEŞ ${ }^{1}$, M. CĂȘVEAN ${ }^{2}$ \\ ${ }^{1}$ University UMFST of Târgu Mureș, Faculty of Engineering, Department of Industrial Engineering and \\ Management, lates.upm@gmail.com \\ ${ }^{2}$ Frontend developer, Accesa IT Systems, Cluj-Napoca, Cluj, marius.casvean@yahoo.com
}

\begin{abstract}
In this paper an experimental study will be carried out, on the influence of geometry, using different compliant mechanical couplings. In the first part of the paper will be presented the compliance of the couplings and a number of consecrated works on this theme will be quoted. The article continues with the case study made on three types of compliant joints. These joints and the mechanics that substitute them will be presented. Towards the end of the paper we explain the experimental method and its results. The final ideas concerning this work will be filled out by conclusions and research directions.
\end{abstract}

\section{Introduction}

\section{The compliance of elastic elements}

Designing and developing any systems based on these type of mechanisms, which are compatible with precision movement, is a necessity in the micro-precision industry. Compliant mechanisms that have proper rotation joints, can provide an excellent accuracy, contrary to conventional rigid mechanisms. The development and manufacture of an effective, monolithic compliant mechanism is a very challenging notion [1]. Compliant mechanism is a good choice when is really wanted to reduce the number of mobile joints. Within this type of articulated mechanisms, the clearance space is inevitable due to designing, manufacturing or assembly processes. It also plays a crucial role and has a significant effect on the stability of the mechanism and performance of the entire system [2]. As an observation of these mechanisms, it can be said that they generally work inappropriately in compression action [3]. In addition to this, it can be said also that the temperature has an influence on the movement of the free-end of the compliant mechanism. Static and dynamic experiments were performed to verify the rationality of the mechanisms in this category [4].

\section{International papers on this subject}

A compliant device was designed by Suhas P. Deshmukh with his team, to amplify the linear motion with a 1:5 scale, using flexible links. The project is a mechanism with square-shaped structure in the joints area. The cross-section of the mechanism is modified from rectangular to U-shaped, thus attempting to reduce the deformation and bending stresses of the entire device. In order to avoid the angular movement of the output link, the input movement is divided into two directions and applied 
perpendicularly to each other, so that their vertical movement is counterbalanced. The material used in this case is copper, due to its excellent elasticity, processability or machining. The linearity and sensitivity of the mechanism make it a suitable candidate for MEMS, stereolithography or 3D printing applications [5].

Lin Cao presents in his work a new optimization technology for designing compliant mechanisms that are effective in transferring movement, strength or energy, while they are strong enough to resist fatigue. The sustained philosophy here is that a compliant mechanism can benefit from the abovementioned properties if flexible hinges are located where they must be and also be dimensioned in a rational way. This requires a design approach that must include criteria based on both efficiency and resistance. Therefore, in the proposed technique, the locations of the couplings and their dimensions were determined simultaneously to meet both rigidity-flexibility criterion (for efficiency) and the power criterion (for force). Both, the theoretical explorations and designing examples, demonstrate that the power of compliant mechanisms can be significantly improved without compromising efficiency and compromise models can be obtained, that are better balanced between efficiency and resistance [6].

\section{Case Study On The Pentalater Mechanism}

\subsection{Couplings made in this work}

An attempt was made to design the hinges of the mechanism, having different geometry, on a pentalater structure. The mechanism that integrates these joints can be seen in Figure 1. This mechanism is made up of kinematic elements, compliant hinges, rigid structure and the end-effector of the mechanism. The motor element of this mechanism consists of two linear piezoelectric actuators which are positioned as shown below. The displacement of the actuators is done by means of a controller and an amplifier [7].

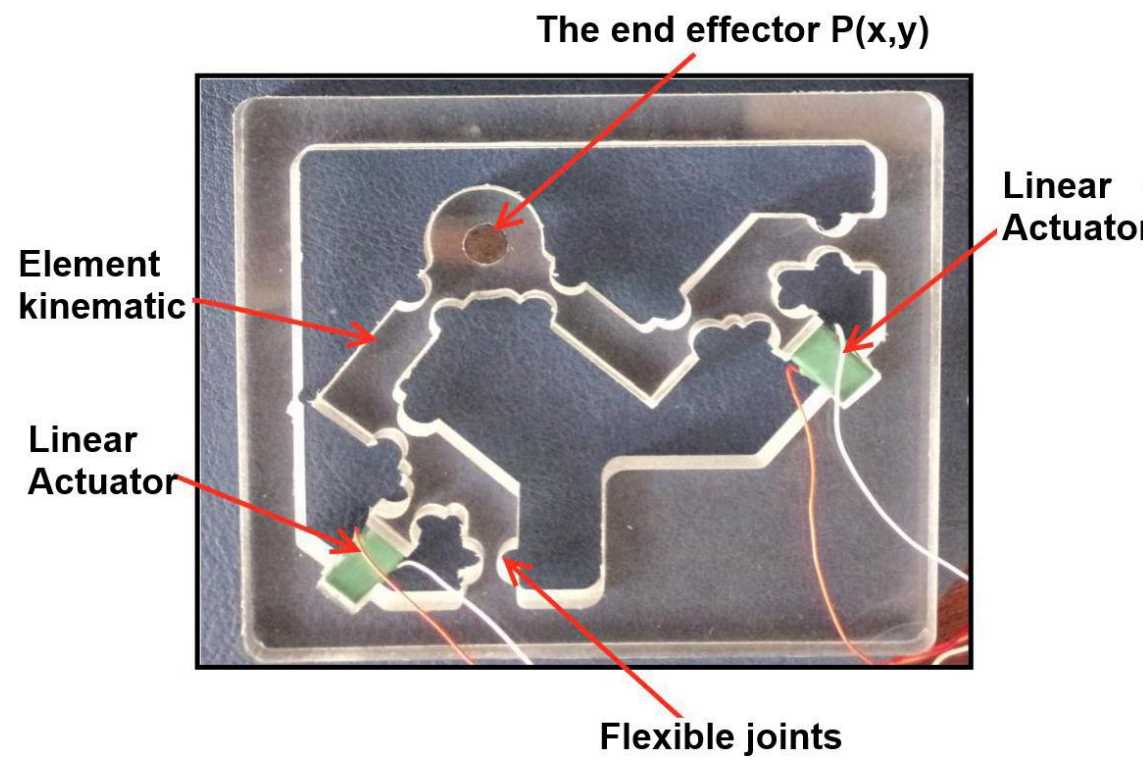

Figure 1. Pentalater mechanism 
Each type of coupling used has the same mechanism as shown in Figure 1. In this paper, each case will be taken for analysis and results will be extracted, in terms of displacement of the moving parts, concluding which variant is more efficient from this point of view. In Figure 2 there are the sets of studied couplings. The precision of the movement and the maximum movement that could be achieved, were followed.

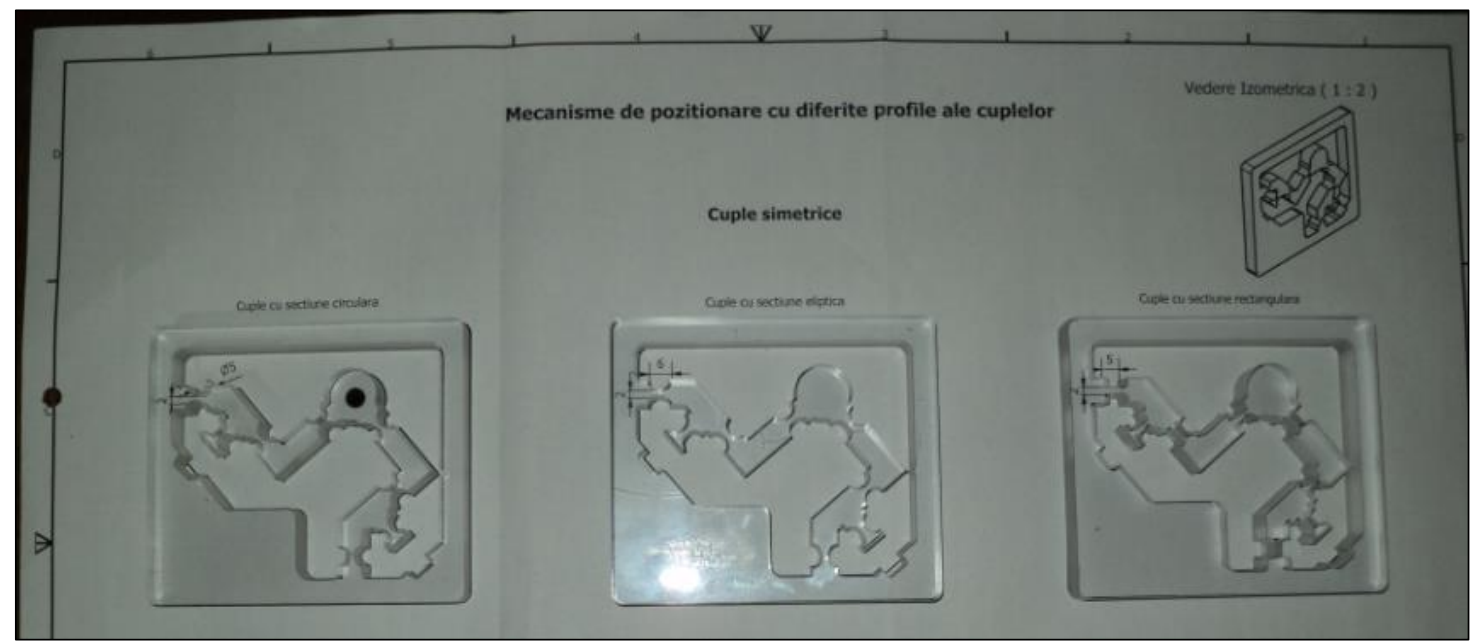

Figure 2. Sets of studied hinges

\subsection{The geometric characteristics of the three studied couplings}

Figure 3 shows the design stage of the mechanism with circular profile hinges (Figure 3a) and its practical realization (Figure $3 \mathrm{~b}$ ).

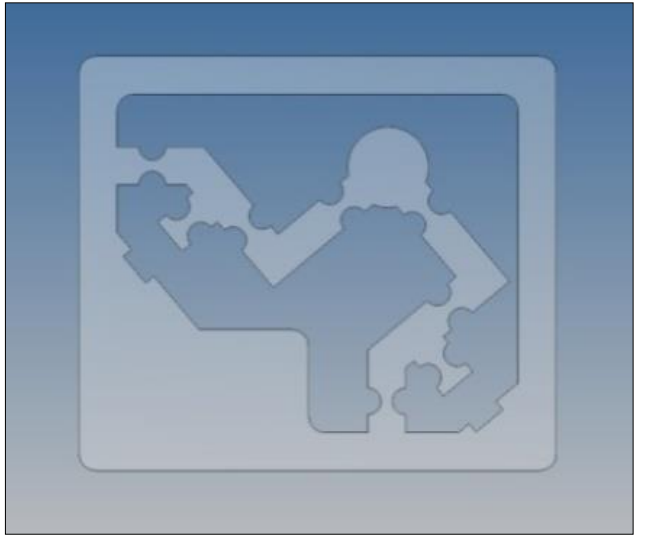

Figure 3a. 3D model

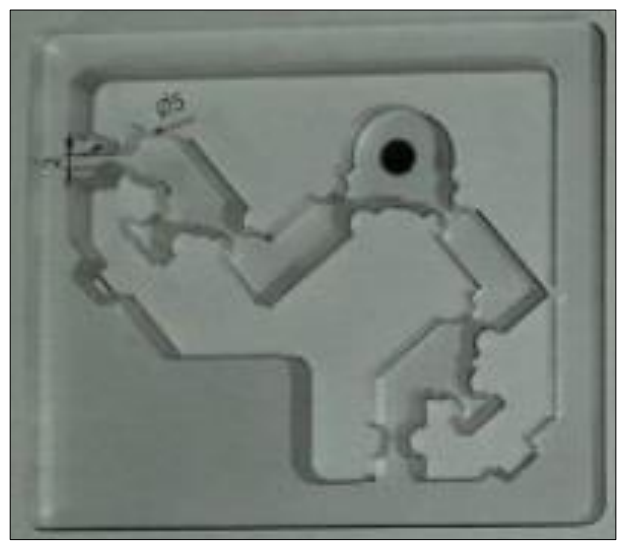

Figure 3b. Physically made model

In Figure 4 it can be seen the design stage of the mechanism with eliptical profile hinges (Figure $4 \mathrm{a}$ ) and its practical realization (Figure $4 b$ ). 


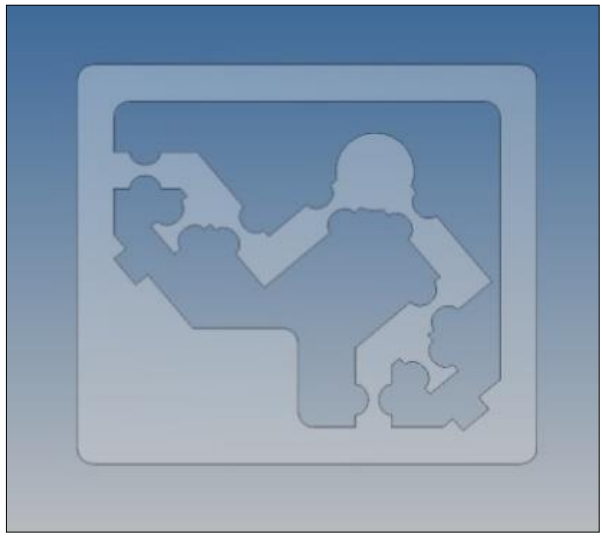

Figure 4a. 3D model

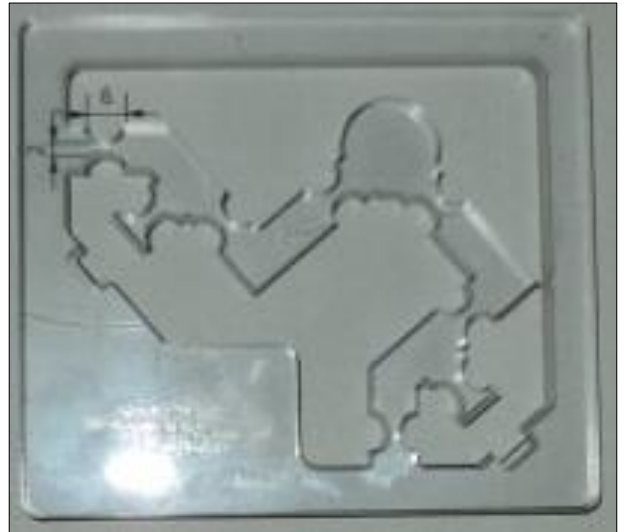

Figure 4b. Physically made model

Last illustrations, Figure 5, shows the design stage of the mechanism with rectangular profile hinges (Figure 5a) and its practical realization (Figure 5b).

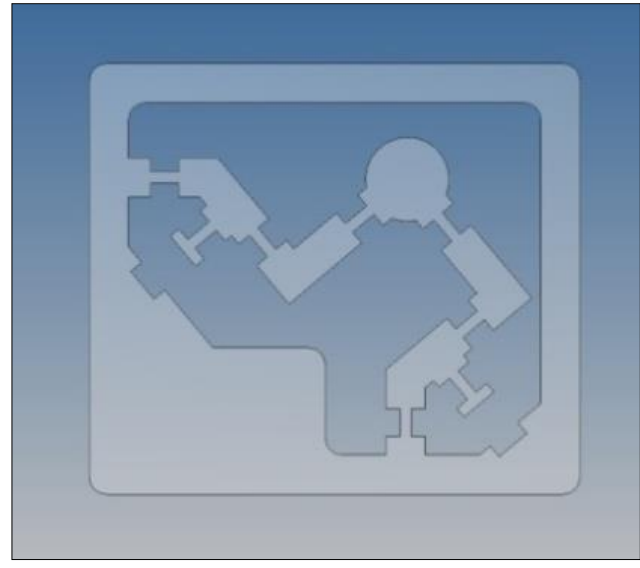

Figure 5a. 3D model

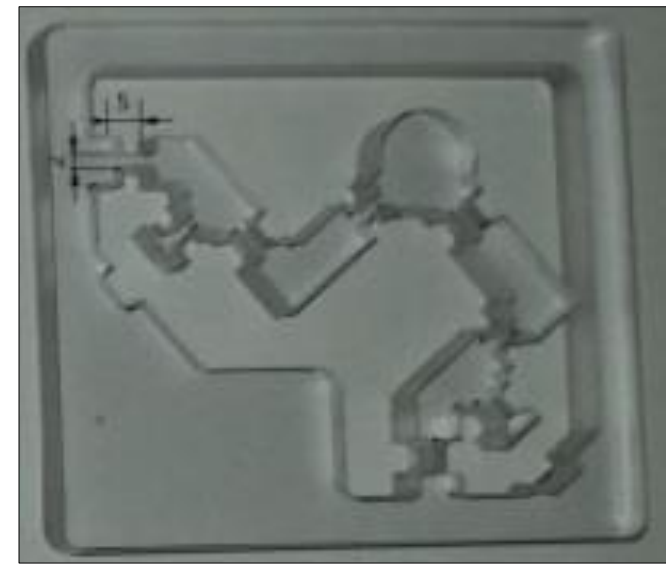

Figure 5b. Physically made model

\section{Case Study On The Pentalater Mechanism}

The experimental study was carried out at the Nyiregyhaza College at the Faculty of Engineering in the same city, from Hungary, in 3D Measurements Laboratory.

The measuring machine was an Axion brand and the software involved for this research was Aberlink 3D. Figure 6 shows the studied mechanisms and the clamping device. The mechanism's actuators are controlled by the Thorlabs amplifier controller, MDT693A model. The actuator displacement values are from $1 \mu \mathrm{m}$ to $9 \mu \mathrm{m}$, the measurements being made in five steps. The measurement method was by touching several points of the end-effector. 
International Journal of Engineering and Management Sciences (IJEMS) Vol. 4. (2019). No. 1

DOI: 10.21791/IJEMS.2019.1.15.

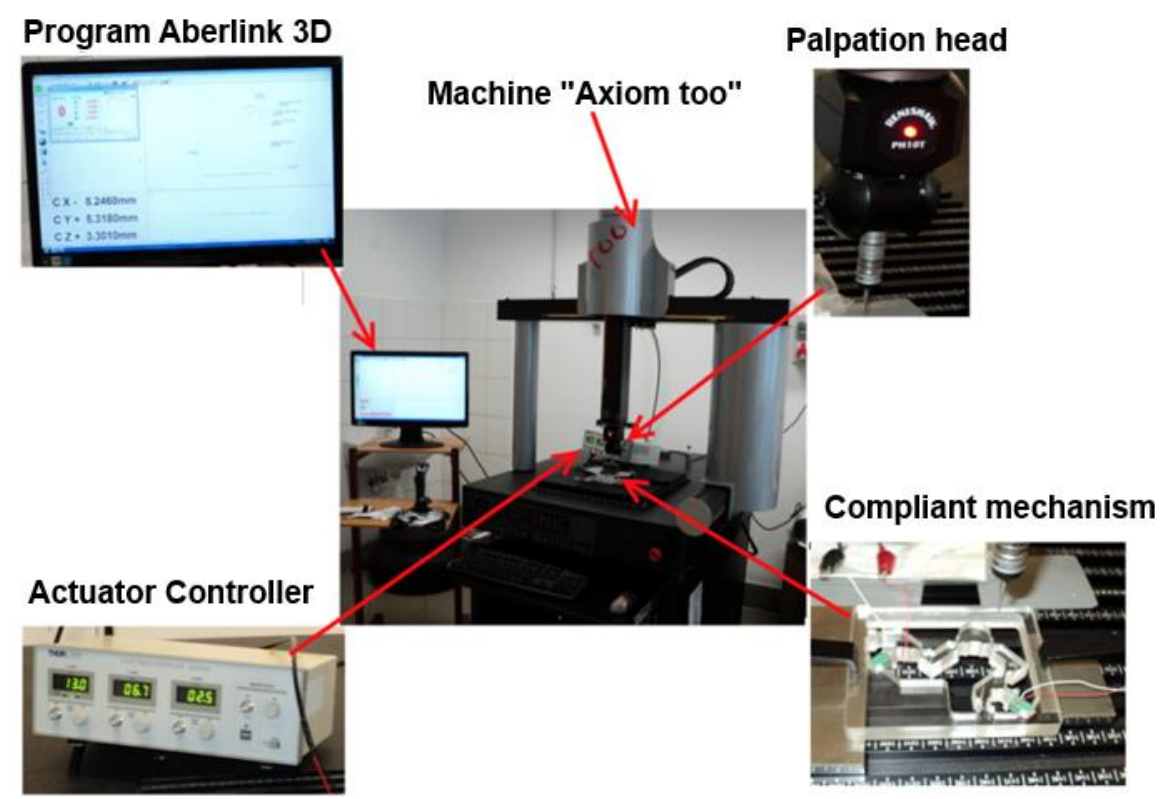

Figure 6. Experimental stand

Graphical data from the experimental case study are found in Figure 7a, for circular profile hinges, Figure 7b, for eliptical profile hinges and Figure 7c, for rectangular profile hinges [8].

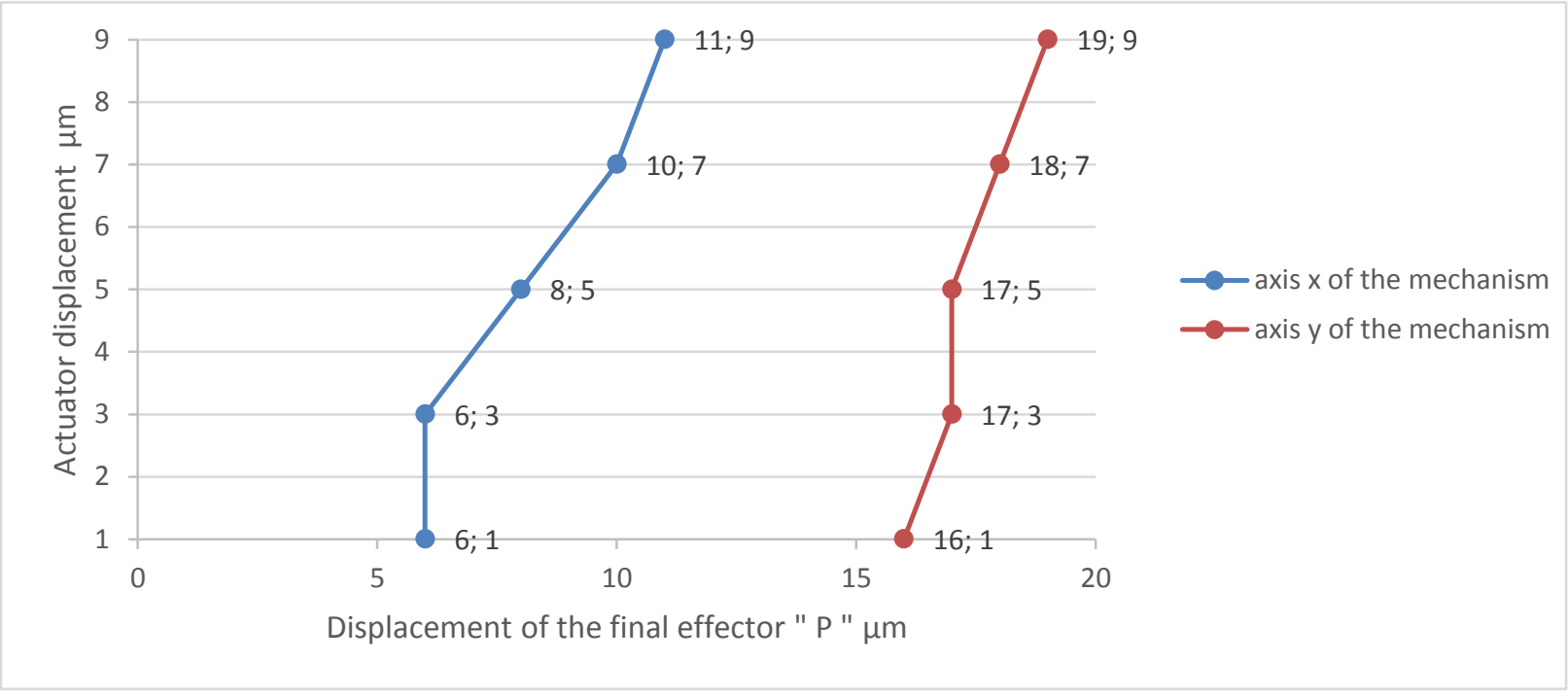

Figure 7a. Circular joint profile 

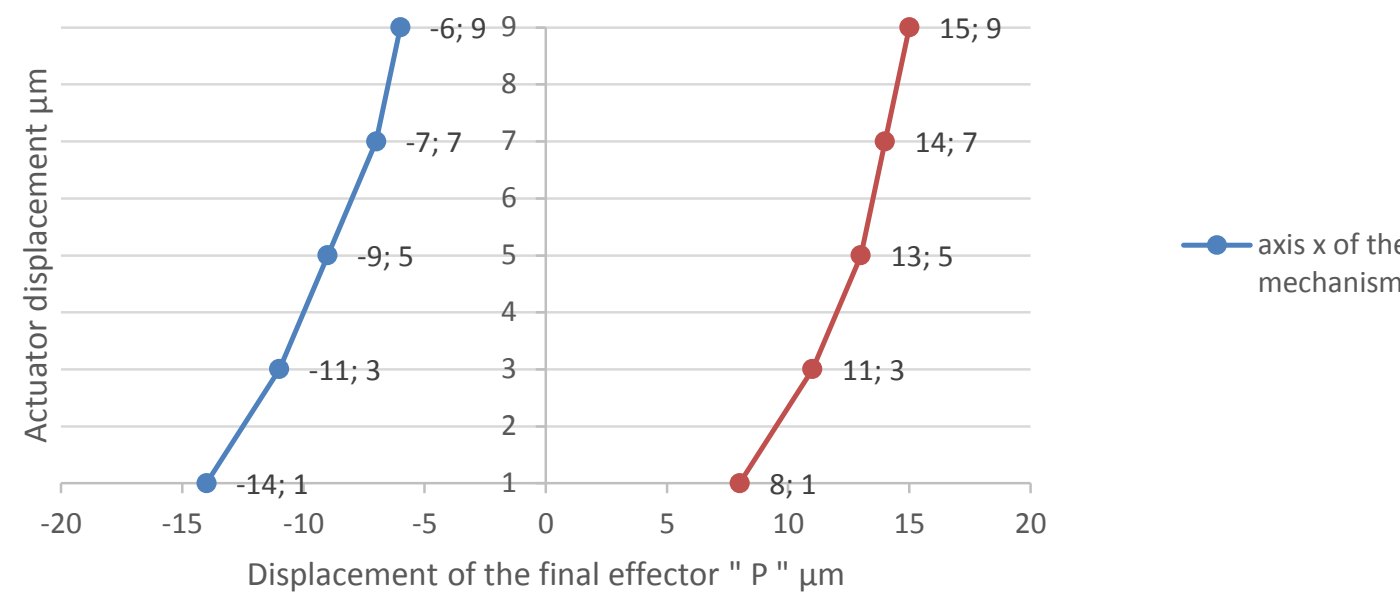
mechanism

Figure 7b. Elliptical joint profile

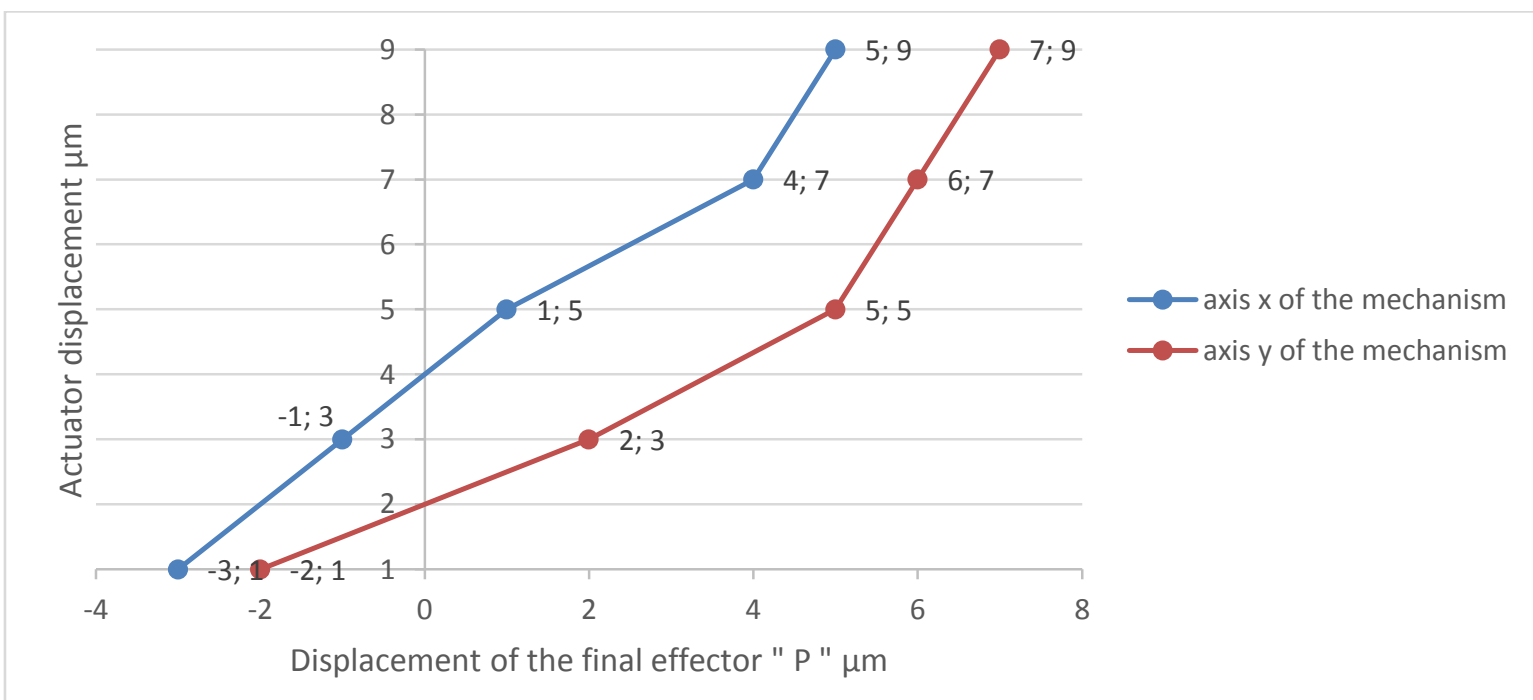

Figure 7c. Rectangular joint profile

\section{Conclusions And Research Directions}

For this study we can conclude that the rectangular shaped hinges have better compliance, followed by eliptical shaped hinges with a medium compliance and the lowest compliance is circular shaped joints. Couplings with good stability from the present study are those with an eliptical profile.

The use of these compliant joints can be easily found in compliant mechanisms that can be useful in mechanical precision applications and special working conditions. An influence on the hinges and why not the entire mechanism, may be the material are made from, aswell as the designed hinge profile, as we saw in this paper.

As future directions, the authors propose to extend this theme of study to a deeper study of hinges stability based on their geometry, the measurement of developed force and the repeatability of the movements on end-effector. Consideration should be given to the joints studies, to integrate these mechanisms into special purpose assemblies. 


\section{Acknowledgements}

We would like to express our gratitude to SC IRUM SA for the moral and financial support for the realization of this article. We also want to thank the organizers of the event for organizing such a scientific conference that helps us publish articles on engineering.

\section{References}

[1] S. A. Srikanth - R. Bhranidaran (2017) Design and Development of Compliant Mechanisms Using Parameterization Technique, International Conference on Advancements in Aeromechanical Materials for Manufacturing (ICAAMM). 4. pp. 7388-7396, Institute of Technology, Hyderabad, Telagana, India.

[2] S. Erkaya - S. Dogan - S. Ulus (2015) Effects of joints clearance on the dynamics of a partly compliant mechanism: Numerical and Experimental studies. Mechanism and Machine Theory. 88. pp.125-140.

[3] J. Dearden - C. Grames - B. D. Jensen - S. P. Magleby - L. L. Howell (2017) Inverted L-Arm Gripper Compliant Mechanism. Journal of Medical Devices. 11.

[4] S. Lin - J. Xu - C. Wang (2017) Synthesis and experiment of a novel parallel compliant mechanism with one translation and two rotations. Proceedings of the Institution of Mechanical Engineers, Part C: Journal of Mechanical Engineering Science. vol. 231.

[5] S. P. Deshmukh - A. A. Paradkar - U. R. Bhamare (2017) Design and Development of Linear Compliant Amplifier based on Flexure Mechanism, International Conference on Advances in Thermal Systems, Materials and Design Engineering (ATSMDE), 2017.

[6] L. Cao - A. T. Dolovich - A. Chen - W. Zhang (2018) Topology optimization of efficient and strong hybrid compliant mechanisms using a mixed mesh of beams and flexure hinges with strength control. Mechanism and Machine Theory. 121. pp. 213-227.

[7] D. Lateș - F. Cioloca (2015) Comparative Analysis Of The Compliant Mechanism Movement With 2 Dof Using Circular, Rectangular, Elliptical Joints. International Scientific Conference O Advances In Mechanical Engineering, 19 November 2015, Debrecen, Hungary, ISBN 978-963-473-917-3.

[8] D. Lateș (2014) Cercetări teoretice și aplicative privind mecanismele compliante folosite în mecatronică, Teza de Doctorat, Cluj-Napoca. 